\title{
Headache in hypertension patients in young rural population of Punjab
}

\author{
ARIF GULZAR ${ }^{1}$, MUHAMMAD ALEEM UD DIN², M FAHEEM SIDDIQUE ${ }^{3}$, RIASAT ALI ${ }^{4}$, ZOYA ARIF ${ }^{5}$ \\ ${ }^{1}$ Associate Professor of Medicine Pak Red Crescent Medical \& Dental College, Lahore. \\ ${ }^{2}$ Assistant Professor of Medicine. Sahara Medical College Norowal \\ ${ }^{3}$ Assistant Professor of Biochemistry, Pak Red Crescent Medical \& Dental College. \\ ${ }^{4}$ Assistant Professor of Anatomy, Pak Red Crescent Medical College Lahore. \\ ${ }^{5}$ Woman Medical Officer, Pak Red Crescent Hospital Lahore \\ Correspondence to: Dr Arif Gulzar, Email drarifgulzar211@gmail.com, Cell: 03454403179
}

\begin{abstract}
Objectives; To find the association of essential hypertension and headache in rural young population of PUNJAB, so as to treat the cases at the earliest stage .

Material and Methods: The study is conducted in medical department of Pak Red Crescent Medical college Dina Nath in the period from October 2020 to June 2021 . fifty four patients including thirty three males and twenty one females with essential hypertension in age group of 18-35 were selected after scrutinizing clinically and on investigations. The patients were then differentiated as those suffering from generalized headaches without any secondary cause of headache were included

Results: Total nineteen patients including seven males out of thirty three males and twelve out of twenty one females in the hypertension patients were having headache. So positivity in males was twenty one percent and in females was fifty seven percent, however in total 19/54 I e 35\% were found having headache.

Conclusions: All the patients with hypertension should be further evaluated for headache and it is not necessary that some secondary cause of hypertension is necessary for headache but there are many other other pathophysiological links which are still to be evaluated.

Keywords: headache, hypertension.migraine, antihypertensive
\end{abstract}

\section{INTRODUCTION}

Headache is a very common symptom in every population. Headache because of acute elevation of hypertension in many cases is considered to be due to some abnormality in hemostasis ${ }^{1,2}$.All these types of headaches are due to some known causes as pheochromocytoma,,paraganglionomas ${ }^{4 a}$ and autonomic dysreflexia $^{5}$ are usually associated with autonomic symptoms . The association of headache and hypertension in migraine is well described but there are other factors than hypertension in etiology of pain, as simple treatment of hypertension is not curative $e^{6,7,8}$ Mostly the people ascribed it to certain underlying causes such as anxiety ,depression ${ }^{9}$, , referred pains due to visual strains , nasal or neck problems and in old people due to cranial arteritis ${ }^{1}$ so many patients have headaches without hypertension so not in need of anti-hypertension treatment ${ }^{10}$. in certain studies on young population hypertension is the cause of headache without any other known cause. ${ }^{11}$.In a study headache in hypertension was found to be directly related to diastolic blood pressure ${ }^{12}$. while in other studies it is inversely related to pulse .pressure ${ }^{11}$. Although mostly patients with chronic hypertension have no physical signs but those with headache nasal bleeds should be keenly observed as they may be hypertensive as it is a silent killer and need antihypertensive treatment ${ }^{13,14}$. In many recent studies the pathophysiology underlying the acute rise in hypertension is at cellular level and it is due to some abnormality mechanically in blood brain barrier ${ }^{15}$. IN the present study we want to observe the association of headaches and hypertension specifically in young population in rural areas so as to save them from this silent killer.

\section{MATERIALS AND METHODS}

Selected the patients in following steps. SECRUTINY . Patients with hypertension in medical out patient door cases in pak red crescent medical college Dina Nath . the patients were in young age group males and females in age range 18-35 and came in opd for minor ailments and found to be hypertensive as per criteria of JNC 8 classification $^{f 1}$ with blood pressure of more than 140/90 . They were further were further evaluated. SELECTION the patients found hypertensive were interviewed and their medical history and clinical examination were performed and relevant investigations are performed as per a Performa to rule out secondary causes of hypertension and fifty four patients with essential hypertension were selected. . the headache was tension type and not hemicranic and not associated with autonomic symptoms/visual problem or any other localized problem as tenderness. They were not associated with vomiting, neck pain or any secondary cause of hypertension as evaluated by clinical features and other investigations. The patients histories are taken and among the group those suffering from headache were separated in a group.

\section{RESULTS}

Table 1: Hypertension cases in age groups 18-35 years

\begin{tabular}{|l|l|}
\hline Male with hypertension & 33 \\
\hline Female with hypertension & 21 \\
\hline Total with hypertension . & 54 \\
\hline
\end{tabular}

So total fifty four patients out of which thirty three are males and twnty one females

Table 2: Hypertension cases with headache Male with hypertension and headache Female with hypertension headache Total with hypertension and headache

\begin{tabular}{|l|l|l|}
\hline $7 / 33$ & $21 \%$ \\
\hline $12 / 21$ & $57 \%$ \\
\hline $19 / 54$ & $35 \%$ \\
\hline
\end{tabular}


So $35 \%$ of our hypertensive patients were suffering from headache. while it is more prevalent in female cases as 12 out of total $21(57 \%)$ as compared to twnty one percent in were were with headache

\section{DISCUSSION}

Many patients in our study were found hypertensive with headache . the headache was tension type. So our study correlates to a long cohort study in France followed for 30 years where headache was associated with high diastolic blood pressure ${ }^{12}$ also the interrelations of low intake of sodium and lower frequency of headache has been found in another study in patients who were taking antihypertensive drugs previously and therefore show an indirect evidence of relationship between headache and hypertension ${ }^{17}$.

\section{CONCLUSIONS}

Headache with hypertension is present in our young population, so every young patient with hypertension and headache should be seriously managed with both non pharmacological and pharmacological measures. There are still some unknown pathophysiological mechanisms for hypertension, for which many basic researches are going on.

\section{REFERENCES}

1. Headache Classification Committee of the International Headache Society (IHS) The international classification of headache disorders, 3rd edition (beta version) Cephalalgia. 2013;33:629-808.

2. Finocchi C, SassosD, . Headache and arterial hypertension. Neurol Sci : official journal of the Italian Neurological Societyand the Italian Society of Clinical Neurophysiology 27;38(Suppl):67-72

3. Pourian M, MustafazadahDB, SoltaniA. Does this patient have pheochromocytoma? A systemic review of clinical signs and symptoms . J.Diab Metab Disoord 2016;15(1):11

4. Balasubramanian G, Nellaiappan V . Functional paragangliomas BMJ case reports 2014;2014:bcr2013203425.

5. Furlan JC. Headache attributed to autonomic dysreflexia : an underrecognized clinical entity . Neurology 2011;77(8): 792 8
6. Bigal ME ,Kurth T, Santanello N , Buse D , Golden W, Rbbins $M$, et;al. Migraine and cardiovascular disease: a population based study. Neurology . 2010;74(8)628-35.

7. C.F Fagemaes, I Heuch, JA Zwart, BS Winswold, MLinde, K . Hagen Eur J Neurol, 2015Jan 22(!) 156-62 blood pressure as a risk factor for headache and migraine :a prospective population based study. Eur J Neurol, 2015Jan 22(!) 156-62

8. Finocchi C , Sassos D. Headache and arterial hypertension . Neurol Sci ; official journal of the Italian Neurological Society and of the Italian Society of Clinical Neurophysiology 2017;38(suppl 1)67-72

9. Jackson CA, Pathirana T, Gardiner PA.Depression anxiety and risk of hypertension in middle age women :a prospective longitudinal study, Hypertens.2016;34, 1959 -1966. 10. Baraldi C, Pellesi L, Guerzoni S, Cainazzo MM, Pini LA Therapeutical approaches to paroxysmal hemicrania, hemicrania continua and short lasting unilateral neuralgiform headache attacks: a critical appraisal. J Headache Pain. 2017 Dec;18(1):71. doi: 10.1186/s10194-017-0777-3. Epub 2017 Jul 20. PMID: 28730562; PMCID: PMC5519518

10. Erlling tornik, Knnut Hagan . Grete Dvb , Turid LingaasHolemaen, Lars Jacob Stovner. Association between blood pressure measures and recurrent headaches in adolescents : cross sectional data from the HUNT -Youth study. J Headache Pain 2011 Jun 12(3)347-353. 12. Courand PY, Serraile M, Gierard N, Demarquay G, Milon H , Lentelme $P$, et.al . The paradoxical significance of headache in Hypertension . Am J Hypertens. 2016;29(9)1109-16

11. Lennart Hansson, MD; David H. G. Smith, MD; Richard Reeves, MD; et alPablo Lapuerta, MD. Headache in mild to moderate Hypertension and its reduction by irbersartan therapy . Arch Intern Med. 2000;160(11):1654-1658. doi:10.1001/archinte.160.11.1654) Eur J Neurol.

12. Friedman BW, Mistry B, West JR, Wollowwitz A THE Association between headache and elevated blood pressure among patients presenting to an ED. Am J Emerg Med 2014;32(9):976-81.

13. Arca KN, Halker Singh RB. The Hypertensive Headache: a Review. Curr Pain Headache Rep. 2019 Mar 14;23(5):30. doi: 10.1007/s11916-019-0767-z. PMID: 30874912.

14. James P,Oparil S, CarterBL , 2014 evidence based guideline for the management of high blood pressure in adults ; report from the panel members appointed to $8^{\text {th }}$ joint National Committee(JNC8). JAMA. 2014 FEB 5311(5):507-20.

15. Chen L, Zhang Z, Chen W , Whelton PK, Appel LJ , lower sodium intake and risk of headache results from the trial of nonpharmacologic intervention in the elderly. Am J Public Health. $2016 ; 106(7): 1270-5$ 